\title{
Dimensões da Sustentabilidade no PPC do Curso de Bacharelado em Administração Pública e Gestão Social da Universidade Federal do Cariri (UFCA)
}

\author{
Alcylanna Nunes Teixeira ${ }^{1}$; Tamyris Madeira de Brito ${ }^{2}$; Erich Costa Saraiva Lobo ${ }^{3}$; \\ Zuleide Fernandes de Queiroz ${ }^{4}$; Paulo Renato Alves Firmino ${ }^{5}$
}

\begin{abstract}
Resumo: O estudo exprime reflexões sobre as propostas político pedagógicas do Curso de Bacharelado em Administração Pública e Gestão Social da Universidade Federal do Cariri (UFCA), de modo especial, a presença de dimensões da sustentabilidade no Projeto Político-Pedagógico de Curso (PPC). A produção de saberes no âmbito da sustentabilidade potencializa o papel acadêmico de conceber os docentes e os discentes enquanto atores responsáveis pelo fomento do Desenvolvimento Regional Sustentável e a fortalece a atuação da Universidade frente ao contexto regional nas ações de ensino, pesquisa, cultura e extensão. O objetivo deste artigo consiste em identificar neste PPC os fatores que revelam, de modo implícito ou explícito, dimensões da sustentabilidade para práticas pedagógicas no referido curso. A metodologia se dá através de uma pesquisa documental, de cunho exploratório, através de um estudo de caso, com ênfase nas ementas de cada disciplina da matriz curricular do curso, seguido do processamento de dados nos softwares RStudio e Iramuteq para melhor compreensão e análise dos dados. Desse modo, identificam-se elementos fortemente alinhados às dimensões da sustentabilidade, ampliando assim as possibilidades de atitudes pedagógicas favoráveis ao Desenvolvimento Regional Sustentável a partir do Curso de Bacharelado em Administração Pública e Gestão Social da UFCA.
\end{abstract}

Palavras-Chave: UFCA. PPC. Administração Pública. Sustentabilidade.

\section{Dimensions of Sustainability in the PPC of the Bachelor's Degree in Public Administration and Social Management of the Federal University of Cariri (UFCA)}

\begin{abstract}
The study expresses reflections on the pedagogical political proposals in the course of Bachelor in Public Administration and Social Management of Federal University of Cariri (UFCA), in particular, the presence of dimensions of sustainability in the political-pedagogical project of course (PPC). The production of knowledge in the context of sustainability enhances the academic role of conceiving the teachers and learners while actors responsible for the Promotion of Sustainable Regional Development and the University forward to the regional context in teaching, research, culture and extension. The objective of this article is to identify in the PPC factors that reveal, implicit or explicit, dimensions of sustainability for pedagogical practices in this course. The methodology is based on an exploratory documentary research, through a case study, with emphasis on the menus of each discipline of the curricular matrix of the course, followed by the data processing in RStudio and Iramuteq softwares for a better understanding and analysis of the data. In this way, it identifies elements strongly
\end{abstract}

\footnotetext{
${ }^{1}$ Mestranda no Programa de Pós-graduação em Desenvolvimento Regional Sustentável (PRODER) pela UFCA. Docente na Faculdade Vale do Salgado (FVS). Icó, CE. alcylannanunes@gmail.com

${ }^{2}$ Mestranda no Programa de Pós-graduação em Desenvolvimento Regional Sustentável (PRODER) pela UFCA. Crato, CE. Docente UNILEÃO. Juazeiro do Norte-CE. tamyris@ leaosampaio.edu.br

${ }^{3}$ Mestrando no Programa de Pós-graduação em Desenvolvimento Regional Sustentável (PRODER) pela UFCA. Crato, CE. erichlobo@gmail.com

${ }^{4}$ Doutora em Educação pela UFC. Professora no Programa de Pós-graduação em Desenvolvimento Regional Sustentável (PRODER) pela UFCA. Crato, CE. zuleidefqueiroz@gmail.com

${ }^{5}$ Doutor em Engenharia de Produção pela UFPE. Professor no Programa de Pós-graduação em Desenvolvimento Regional Sustentável (PRODER) pela UFCA. Crato, CE. paulo.firmino@ufca.edu.br 
aligned with the dimensions of sustainability, thus increasing the possibilities of pedagogical attitudes conducive to sustainable regional development from the course of Bachelor in Public Administration and Social Management of the UFCA.

Keywords: UFCA. PPC. Public Administration. Sustainability.

\section{Introdução}

Os estudos sobre sustentabilidade atualmente encontram-se pautados não somente no bem-estar e crescimento econômico, mas também no respeito a natureza, na transversalidade da ciência, dos impactos tecnológicos e da ética na relação homem-ambiente. As transformações requerem utilização de diferentes recursos didáticos, e desse modo é possível incitar o olhar aos impactos da globalização e das evoluções tecnológicas para pensar estratégias sustentáveis a longo prazo (BURSZTYN, 2001).

Sachs desenvolveu seus estudos na perspectiva de sustentabilidade que abrange aspectos sobre ecodesenvolvimento, respeitando a importância dos recursos naturais e ambientais, no entanto, passou a ampliar a visão de desenvolvimento para a perspectiva sustentável, compreendendo a integralidade das dimensões social, econômica, ecológica, espacial e cultural. Desse modo, pensar desenvolvimento sustentável é então apontar para a universalização efetiva dos direitos humanos (SACHS, 2008).

As mudanças convocam a humanidade a superar os atuais paradigmas socioeconômicos, pois tampouco se sustentarão as demandas ambientais e humanas que emergem na contemporaneidade. Para Sachs (2008) faz-se necessário abordar os problemas sociais de maneira holística, não se detendo apenas no manejo da gestão dos recursos naturais, mas também ampliando as possibilidades de transformações do padrão civilizatório contemporâneo.

Desta feita, a expressão sustentabilidade denota a importância que deve ser dada ao resgate do equilíbrio dos ecossistemas, por meio de um desenvolvimento que preze pela manutenção da biodiversidade. Abraçando a globalização como um fato consolidado a partir do início do século XXI, a metropolização dos grandes centros urbanos e a mundialização dos fluxos de capital deve buscar seguir uma alternativa que minimize e não acentue ainda mais as desigualdades regionais (BENKO, 2002).

568 Id on Line Rev. Mult. Psic. V.13, N. 46 p. 567-583, 2019 - ISSN 1981-1179 Edição eletrônica em http://idonline.emnuvens.com.br/id 
A utilização do processo de desenvolvimento sustentável visa alcançar a sustentabilidade de um determinado sistema global. Os governos mundiais que estabeleceram o compromisso de aplicar políticas públicas no sentido de contemplar os Objetivos para o Desenvolvimento Sustentável-ODS, preocupam-se menos com o crescimento e mais com um desenvolvimento econômico que tenha como indissociáveis as pautas ambientais e sociais.

A educação para a sustentabilidade ou, em terminologia considerada mais apropriada a ecoeducação, ganha visibilidade desde a década de 70 do século XX, quando da realização da Conferência de Estocolmo, na Suécia. Conhecida como a primeira Conferência Mundial de Meio Ambiente, dentre outras pautas importantes, trouxe como uma das pautas, a importância de educar o cidadão para a preservação do meio ambiente. Considera-se que, a partir desta conferência, surge o que pode ser denominado por educação ambiental, apresentada como instrumento de efetivação do direitos humanos de terceira dimensão, relacionados ao meio ambiente ecologicamente equilibrado (REIGOTA, 2001).

Nesse sentido, este estudo objetiva abordar as dimensões da sustentabilidade presentes no PPC do Curso de Bacharelado em Administração Pública e Gestão Social da Universidade Federal do Cariri da UFCA. Partindo do pressuposto da presença de uma preocupação com os Objetivos para o Desenvolvimento Sustentável-ODS e da estruturação do Curso por meio da previsão neste PPC de uma identidade e de uma vocação do Curso para a promoção do desenvolvimento territorial sustentável da Região Metropolitana do Cariri (RMC).

A expressão desenvolvimento territorial sustentável engloba três núcleos com cargas semânticas bastante significativas para a compreensão do lema do curso e das habilidades e competências que este Bacharelado pretende alcançar quando da estruturação da sua política pedagógica.

O referido curso foi criado em setembro de 2010 pela Resolução do CONSUNI/UFC $\mathrm{n}^{\circ}$ 28, de 30/09/2010, intitulado Bacharelado em Administração Pública, com ênfase em Gestão Pública e Social. A proposta da implementação de um PPC alinhado com os ODS, pode apontar para o diferencial desta graduação, alicerçada em dois eixos: Eixo 1 democracia e sociedade e Eixo 2 - estado e governança pública. Desta feita para compreender e analisar a identidade, os objetivos e a estruturação deste Bacharelado, analisar-se-á o discurso presente no texto do PPC, para um alcance preciso da relevância dada às dimensões da sustentabilidade e aos Objetivos para o Desenvolvimento Sustentável-ODS.

569 Id on Line Rev. Mult. Psic. V.13, N. 46 p. 567-583, 2019 - ISSN 1981-1179 Edição eletrônica em http://idonline.emnuvens.com.br/id 
No tocante ao método, faz-se uso aqui da pesquisa documental, com caráter descritivo e exploratório, através de um estudo de caso, por meio da análise do Projeto PolíticoPedagógico do Curso de Bacharelado em Administração Pública e Gestão Social, disponibilizado por meio da plataforma virtual da Universidade Federal do Cariri-UFCA, bem como as especificidades sobre sustentabilidade no ementário de cada disciplina, caracterizando assim, a amostra intencional da pesquisa desenvolvida.

Especificamente, com esse propósito será inicialmente realizada uma breve incursão histórica acerca do conceito de desenvolvimento e da previsão dos Objetivos para o Desenvolvimento Sustentável, atrelando este marco histórico-teórico a outros três conceitos forjados no cenário internacional de debates acerca da preocupação com as três dimensões do desenvolvimento - a dimensão econômica, a social e a ambiental. Serão abordados ainda os conceitos de território e de sustentabilidade, pois o desenvolvimento territorial sustentável é impresso do PPC como identificador da essência do Bacharelado em comento.

\section{Desenvolvimento e Sustentabilidade}

Segundo José Eli da Veiga (2015), o conceito de desenvolvimento ganha relevo no cenário de debates internacionais a partir do fim da Segunda Guerra Mundial, atrelado a ideia de recuperação das nações devastadas pelas consequências danosas desse conflito de expressão incomensurável. A bipolarização do mundo reforça-se com a divisão entre países socialistas e países capitalistas e uma corrida armamentista e aeroespacial dão o tom da preocupação com o desenvolvimento atrelado a um crescimento intensivo.

Desenvolvimento é encarado como crescimento do Produto Interno Bruto-PIB. Quanto maior o PIB de uma nação, mais desenvolvida a mesma será. Porém o PIB, já no início da década de 70, perde credibilidade frente a outros indicadores como o GPI-Indicador de Progreso Genuíno, proposto pelos economistas Daly e Cobb. De maneira simultânea o PNUD-Programa das Nações Unidas para o Desenvolvimento lança o Índice de Desenvolvimento Humano-IDH, que assim como o GPI tentava "corrigir e "ajustar" as discrepâncias do PIB (VEIGA,2015).

O IDH resulta da média aritmética entre o PIB de uma coletividade e dois indicadores sintéticos sobre o acesso de sua população à saúde e educação. Tal medida de correção busca 
contemplar uma nova ideia referente ao desenvolvimento, clarificada por Armatya Sen. Para o economista indiano, laureado com o prêmio Nobel de Economia em 1998, o desenvolvimento está relacionado intrinsecamente a expansão das liberdades substantivas (ARMATYA, 2000).

Para Ignacy Sachs em sua obra Caminhos para o Desenvolvimento Sustentável, a sustentabilidade aponta para uma mudança de paradigma a partir do conceito de desenvolvimento, diante do limiar no duplo imperativo ético: "a solidariedade sincrônica com a geração atual e a solidariedade diacrônica com as gerações futuras" (2009. p.75).

Sustentabilidade não é sinônimo de Desenvolvimento Sustentável, porém os dois conceitos são indissociáveis. No Programa das Nações Unidas para o DesenvolvimentoPNUD foram almejados os Objetivos para o Desenvolvimento do Milênio-ODM. Já em 2015 o Programa das Nações Unidas Para o Meio Ambiente-PNUMA, através da Agenda 2030, fez com que os ODM fossem substituídos pelos Objetivos para o Desenvolvimento Sustentável. Os ODS totalizam 17 Objetivos do Desenvolvimento Sustentável. A Agenda 2030 compreende 169 metas que serão alcançadas com a implementação dos objetivos através de parcerias globais, seguidas de um arcabouço para acompanhamento e revisão das ações (VEIGA, 2015).

No Brasil, o documento de referência do I Conferência Nacional de Desenvolvimento Regional trata sobre os conceitos de desenvolvimento, de sustentabilidade e de desenvolvimento sustentável. Segundo o documento de referência, é inaceitável o modelo de crescimento de exploração indiscriminada de recursos naturais, pois este compromete o planeta para as gerações futuras (BRASIL, 2012).

Assim, não há mais lugar para elaboração de políticas de desenvolvimento setorial e espacial, urbano e regional, sem que se considerem, simultaneamente, a sustentabilidade social e ambiental. Tal restrição passa a exigir padrões diferentes de consumo assim como muita precaução, técnica e racionalidade nos usos dos recursos naturais, especialmente da água e de fontes geradoras de energia, preocupando-se sempre com destino final dos resíduos.

Coloca-se assim um grande desafio às estratégias de desenvolvimento de nações e regiões economicamente atrasadas, posto que, candidatas como são à inclusão econômica, se deparam com um condicionante ambiental criado historicamente por outras regiões que já se encontram na dianteira do processo de desenvolvimento. Por outro lado, a nova consciência ambiental que cresce a cada dia, traz também oportunidades que podem e devem ser consideradas nas estratégias de desenvolvimento destas regiões. Esta nova consciência cria importantes segmentos de mercado para alimentos, energias e outros bens que tragam a marca da 
sustentabilidade social e ambiental. Além disso, os esforços tecnológicos necessários para desenvolver formas mais sustentáveis de produção podem promover círculos virtuosos de crescimento sustentados através de inovações (BRASIL, 2012).

A sustentabilidade não está correlacionada exclusivamente a um ou outro ponto de vista em específico, mas se encontra em expansão e assume multifaces que, quando consideradas em conjunto, poderão estimular uma transformação individual no sentido de oportunizar a cada pessoa a desenvoltura de potenciais necessários a uma melhor qualidade de vida.

Sachs (2004) expressa sua não preocupação semântica, mesmo com o desejo de englobar todos os aspectos discutidos em torno as dimensões da sustentabilidade em um pacote de "desenvolvimento total", segue com o olhar para a aplicabilidade das expressões, onde desenvolvimento sustentável integra as dimensões, biológica, social, política, econômica, ecológica, espacial e cultural, que alicerçam as condições básicas necessárias à sustentabilidade.

Assim é perceptível que os conceitos de desenvolvimento, sustentabilidade e desenvolvimento sustentável, estreitam-se com os conceitos de justiça social, de liberdade, de direitos sociais e de acesso à educação. O desenvolvimento sustentável alinha-se a uma educação para a sustentabilidade, ou como preferem alguns autores, a uma ecoeducação.

\section{Educação para a Sustentabilidade}

A partir da compreensão de desenvolvimento como liberdade e justiça social é possível aliar o conceito de desenvolvimento ao conceito de sustentabilidade. Segundo Klaus Bosselmann, (2015, p. 25-26) "o termo sustentabilidade desencadeia uma resposta semelhante ao termo justiça. Todo mundo concorda com isso, mas ninguém parece saber muito sobre". Assim o autor afirma que a sustentabilidade é absorvida apenas como uma vaga ideia do que se trata ou de como poderia ser alcançada. É possível idealizar uma sociedade sustentável, porém é muito difícil concretizar meios para atingi-la.

A palavra sustentabilidade, como substantivo, segundo VEIGA (2015) consagra-se como um valor, atrelado a preocupação, não apenas com os presentes, mas especialmente com as futuras gerações, o que está para além de reconhecer as expressivas contribuições de curto e médio prazo, mas sim compreender e se apropriar de condutas que impliquem também em

572 Id on Line Rev. Mult. Psic. V.13, N. 46 p. 567-583, 2019 - ISSN 1981-1179 Edição eletrônica em http://idonline.emnuvens.com.br/id 
práticas sustentáveis a longo prazo, prevenindo demandas de sustentabilidade que possam atingir a outrem.

Nesse sentido, compreender desenvolvimento sustentável é ampliar o campo de alcance da interdisciplinaridade, refletir sobre a condição humana de pertencimento e potencial. Jara e Souto (2001) expressam a necessidade de submergir em dimensões intangíveis que apontam para além dos fatores explícitos, ressaltando aspectos implícitos e subjetivos do desenvolvimento sustentável, ressaltando a importância do capital social, cultural e humano no processo de desenvolvimento sustentável.

As discussões no âmbito do desenvolvimento sustentável englobam de modo significativo a educação ambiental na universidade, em uma perspectiva que proporciona também a ampliação do olhar para o desenvolver e potencializar a consciência ambiental de futuros profissionais (MARCOMIN; SILVA, 2009).

Nesta tônica de desenvolver a compreensão da importância da sustentabilidade para a continuidade da vida na terra, a inserção do valor sustentabilidade perpassa a alteração dos currículos da Educação Básica, do Ensino Médio e da Educação Superior, no sentido de inserir uma educação para a sustentabilidade nesses currículos. Em relação aos cursos de Graduação no Brasil algumas Leis indicam quais os caminhos a serem seguidos para atingir os objetivos da Educação Superior

A Lei no 9.394, de 20 de dezembro de 1996-Lei de Diretrizes e Bases da Educação LDB trata em seu art. 43 que a Educação Superior tem como precípua finalidade "estimular a criação cultural e o desenvolvimento do espírito científico e do pensamento reflexivo", no rol deste art. 43 cita ainda que é finalidade da Educação Superior, a inserção dos alunos egressos em setores profissionais e para a participação no desenvolvimento da sociedade brasileira, e colaborar na sua formação contínua (BRASIL, LDB, 1996).

Segundo Freire a importância da educação "vai crescendo na medida sobretudo em que a gente descobre outra obviedade que é a seguinte: não é o discurso, a oralidade, o que ajuíza a prática, mas ao contrário, é a prática quem ajuíza o discurso" (FREIRE, 1982, p. 93).

Desta feita, alinhar a educação para a sustentabilidade nos PPCs e no ementário, bem assim nas práticas pedagógicas docentes, por meio de uma didática preocupada com a ecoeducação, pode apontar para a realização de práticas racionais de prevenção das ações predadoras, em prol da manutenção do equilíbrio do meio ambiente ecologicamente equilibrado.

573 Id on Line Rev. Mult. Psic. V.13, N. 46 p. 567-583, 2019 - ISSN 1981-1179 Edição eletrônica em http://idonline.emnuvens.com.br/id 


\section{Alinhamento do PPC do curso de Administração Pública da UFCA às dimensões da Sustentábilidade}

Antes de imiscui-se nos meandros jurídicos do Curso de Bacharelado em Administração Pública da UFCA, tratar-se-á, de maneira breve sobre as diretrizes para a criação e para a implementação dos cursos de Bacharelado em Administração Pública e Gestão Social da UFCA.

A resolução de $n^{\circ} 1$ de 13 de Janeiro de 2014, do Conselho Nacional de EducaçãoCNE, que institui e disciplina as Diretrizes Curriculares Nacionais do curso de graduação em Administração Pública, dispõe em seu artigo art. $5^{\circ}$ que o curso de graduação em Administração Pública necessita contemplar em seus projetos pedagógicos e na organização da sua matriz curricular "conteúdos que revelem, em uma perspectiva histórica e contextualizada, compromisso com os valores públicos e o desenvolvimento nacional, assim como com a redução das desigualdades [...]”, tal previsão curricular deve preocupar-se ainda com o reconhecimento dos desafios derivados da diversidade regional e cultural (BRASIL, 2014).

Ainda em relação a Resolução supracitada, sobre o que dispõe em seu art. $6^{\circ}$, tem-se que alguns conteúdos de formação possuem caráter básico e devem ser contemplados no ementário das disciplinas. Tem-se como conteúdo de formação básica os relacionados à característica multidisciplinar da área Pública, articulando conteúdos de Administração, de Ciências Contábeis, de Ciência Política, de Economia, de Direito e de Sociologia; os estudos antropológicos, filosóficos, psicológicos, ético-profissionais, bem como os relacionados às tecnologias da comunicação e da informação; os conteúdos relacionados à capacidade de leitura, escrita, expressão e comunicação; e por fim aqueles conteúdos relacionados, nas diferentes áreas disciplinares, à realidade histórica e contemporânea da sociedade e do Estado brasileiros.

Os parágrafos $3^{\circ}$ e $4^{\circ}$ do mencionado art. $6^{\circ}$ da Resolução $n^{\circ} 1$ de 2014 do CNE, afirmam que os conteúdos de formação profissional deverão incluir aqueles sobre governos e políticas públicas comparadas, conteúdos metodológicos, abrangendo estudos quantitativos e qualitativos, e conteúdos complementares ou especializados, oferecendo ao formando a opção de aprofundar-se por meio de estudos de caráter transversal e interdisciplinar. Tais poderão

574 Id on Line Rev. Mult. Psic. V.13, N. 46 p. 567-583, 2019 - ISSN 1981-1179 Edição eletrônica em http://idonline.emnuvens.com.br/id 
ser oferecidos de forma simultânea, não requerendo, necessariamente, uma sequência compulsória, a critério de cada Instituição.

A par desses dados vê-se que o curso de Bacharelado em Administração Pública e Gestão Social da UFCA foi criado em setembro de 2010 pela Resolução do CONSUNI/UFC $\mathrm{n}^{\circ}$ 28, de 30/09/2010, intitulado Bacharelado em Administração Pública, com ênfase em Gestão Pública e Social.

A proposta da implementação de um Projeto Pedagógico do Curso-PPC, alinhado com os Objetivos para o Desenvolvimento Sustentável-ODS demonstra-se como o diferencial desta graduação, uma vez que em relação à Resolução n $^{\circ} 1$ de 2014 do CNE nada é disposto acerca dos ODS e sequer há uma preocupação em abordar os paradigmas da sustentabilidade, do desenvolvimento sustentável ou da educação ambiental como temáticas presentes nas disciplinas obrigatórias, no desenvolvimento das competências e habilidades ou mesmo no estabelecimento daquilo que deve ser contemplado nos projetos políticos pedagógicos. Do que pode inferir-se que a Resolução do CONSUNI/UFC $n^{\circ} 28$, de 30/09/2010, anterior à Resolução $\mathrm{n}^{\mathrm{o}} 1$ de 2014 do CNE, demonstra-se precursora na relevância dos ODS para o estabelecimento de um projeto político pedagógico alinhado às diretrizes da educação ambiental estabelecidas pela UNESCO.

O PPC do curso está alicerçado em dois eixos: Eixo 1 - democracia e sociedade e Eixo 2 - estado e governança pública. Desta feita para compreender e analisar a identidade, os objetivos e a estruturação deste Bacharelado, analisar-se-á as o discurso presente no texto do PPC, para um alcance preciso da relevância dada às dimensões da sustentabilidade e aos ODS.

O PPC do Curso foi revisado em 11 de novembro de 2015, o documento fora então publicado com a sua nova versão, onde o colegiado assim expõe:

\footnotetext{
Passados cinco anos da sua implementação, impôs-se a necessidade de revisão naquilo que as DCNs de Administração não permitiram avançar e na atualização da sua matriz curricular e concepção pedagógica em consonância com as DCNs próprias de Administração Pública, aprovadas em 10/12/2010 pelo CNE/CES, conforme parecer 266/2010 e homologadas pelo ministro da educação através da Resolução CNE/CES No 1 de 13 de janeiro de 2014. Assim, este novo PPC afirma a identidade e a vocação do Curso para a promoção do desenvolvimento territorial sustentável da Região do Cariri, através da formação de caráter generalista, capaz de preparar profissionais qualificados para atuar na esfera pública ampliada com base em uma visão holística das práticas de gestão do setor público governamental e não governamental (BRASIL, 2015).
} 
Nesse sentido, a matriz curricular no Curso foi pensada a partir dos dois grandes eixos temáticos, o Eixo 1 e Eixo 2, composto por unidades curriculares específicas, além das suas áreas transversais. O Eixo 1 no que se refere a Democracia e Sociedade, agrega as unidades curriculares de Estado e Sociedade e Gestão Social. O Eixo 2 contempla Estado e Governança Pública através da concentração das unidades curriculares de Gestão Pública e Políticas Públicas e Contabilidade e Finanças Públicas.

Complementar a esses, agrega-se então um outro eixo que compete às áreas transversais, compostas pelas unidades curriculares de Direito, 1 Resolução CNE/CES 1/2014. Diário Oficial da União, Brasília, 13 de janeiro de 2014 - Seção 1 - pp. 17-18. 7 Economia, Metodologia de Pesquisa e Administração. As disciplinas são distribuídas em unidades curriculares, contemplando os principais temas e abordagens dentro do campo multidisciplinar da Administração Pública, como orientam as suas DCNs, incluindo a disciplina de Libras e outras transversais, sejam como disciplina ou temas específicos nos conteúdos programáticos, além de considerar os componentes gerais compostos por: (i) Residência Social (Estágio); (ii) Trabalho de Conclusão de Curso - TCC e (iii) Atividades Complementares.

No PPC, que contempla 110 páginas, é possível observar diretamente a expressão do termo sustentabilidade citada por 28 vezes, destas, no que se refere especificamente ao ementário identifica-se o termo citado 21 vezes, sendo 1 em título de disciplina, 4 em ementas, 4 em objetivos que compõem as disciplinas. Entendendo assim, quão explícito se torna a atenção para a sustentabilidade que é dada na proposta pedagógica do Curso.

Das disciplinas expostas ao ementário, entre obrigatórias e optativas, 8 contemplam em seu plano curricular, ora como referências básicas, ora como complementares, bibliografias que discutem diretamente Sustentabilidade, a partir dos estudos de HOLMGREN (2013); CUNHA (2012); DIAS (2011); PEREIRA (2011); PUPPIM (2008); CHACON (2007); BELLEN (2005); BURSZTYN (2001); tornando relevante as reflexões e as práticas na perspectiva da sustentabilidade, compreendendo as dimensões para além da Econômica, Social e Ambiental, mas também as dimensões cultural e de capital humano, dentre outras e perspectivas éticas da corresponsabilidade por outrem.

No Quadro 1 é possível visualizar a caracterização das disciplinas que apontam diretamente o termo sustentabilidade na construção da proposta pedagógica disciplinar, compreendendo a dedicação estrutural curricular para com o Desenvolvimento territorial 
Sustentável, de modo especial da RMC a partir das dimensões da Sustentabilidade fortalecidas no âmbito acadêmico-pedagógico e social.

Quadro 1 - Caracterização de disciplinas com a presença do termo sustentabilidade em sua proposta pedagógica.

\begin{tabular}{|c|c|c|c|c|c|c|}
\hline DISCIPLINAS & $\begin{array}{c}\text { Tipo de } \\
\text { Unidade } \\
\text { Curricular }\end{array}$ & $\begin{array}{c}\text { CR } \\
*\end{array}$ & Objetivos & Ementa & $\begin{array}{c}\text { Referência } \\
\text { Básica }\end{array}$ & $\begin{array}{c}\text { Referência } \\
\text { Compleme } \\
\text { ntar }\end{array}$ \\
\hline $\begin{array}{c}\text { FUNDAMENTOS DA } \\
\text { ECONOMIA }\end{array}$ & Obrigatória & 4 & 1 & 0 & 1 & 0 \\
\hline $\begin{array}{c}\text { DESENVOLVIMENTO E } \\
\text { SUSTENTABILIDADE }\end{array}$ & Obrigatória & 4 & 2 & 2 & 2 & 1 \\
\hline $\begin{array}{c}\text { GESTÃO SOCIAL E } \\
\text { TERRITÓRIO }\end{array}$ & Obrigatória & 4 & 0 & 1 & 1 & 0 \\
\hline $\begin{array}{c}\text { OFICINA TEMÁTICA 5: } \\
\text { ÉTICA, CONTROLE } \\
\begin{array}{c}\text { SOCIAL E } \\
\text { TRANSPARÊNCIA }\end{array}\end{array}$ & Obrigatória & 4 & 1 & 0 & 0 & 0 \\
\hline $\begin{array}{c}\text { OFICINA TEMÁTICA 6: } \\
\text { ANÁLISE DE } \\
\text { INDICADORES }\end{array}$ & Obrigatória & 4 & 1 & 0 & 1 & 1 \\
\hline $\begin{array}{c}\text { GESTÃO DAS } \\
\text { ORGANIZAÇÕES } \\
\text { SOCIAIS E POLIITICAS } \\
\text { NÃO-ESTATAIS }\end{array}$ & Optativa & 4 & 0 & 1 & 0 & 0 \\
\hline $\begin{array}{c}\text { TECNOLOGIAS } \\
\text { SOCIOAMBIENTAIS E } \\
\text { PERMACULTURA }\end{array}$ & Optativa & 4 & 0 & 0 & 1 & 1 \\
\hline $\begin{array}{c}\text { GESTÃO AMBIENTAL E } \\
\text { ORGANIZAÇÕES }\end{array}$ & Optativa & 4 & 0 & 0 & 1 & 2 \\
\hline
\end{tabular}

*CR - Créditos.

Destaca-se então a disciplina obrigatória intitulada Desenvolvimento e Sustentabilidade, ofertada no $2^{\circ}$ semestre do Bacharelado em Administração Pública, que conta com a germinação da sustentabilidade no Curso, através de 48h/a teórica e 16h/a prática, totalizando 64 horas aula, sendo distribuídos em 4 créditos semanais.

\footnotetext{
A trajetória do conceito de desenvolvimento no mundo. Desenvolvimento versus Crescimento. Sustentabilidade e suas dimensões. Ecodesenvolvimento e sustentabilidade socioambiental. Arranjos institucionais e políticas ambientais. Desequilíbrios ecossistêmicos urbanos e rurais. História das estratégias de intervenção no Brasil: pressupostos teóricos; Experiências regionais de desenvolvimento no Brasil (TAVARES, 2016, p.40).
}

Essa unidade curricular, expressa de modo representativo a sustentabilidade, não só em sua ementa, mas também em seus objetivos, recorrente em dois momentos e 
harmonizando com duas referências básicas e uma complementar, coadunando de modo sustentável com a proposta geral da disciplina. Desse modo, podemos contemplar a nuvem de palavras que se mostram mais representativas nesse contexto, como segue na imagem 1 :

Imagem 1: Nuvem de palavras representativas

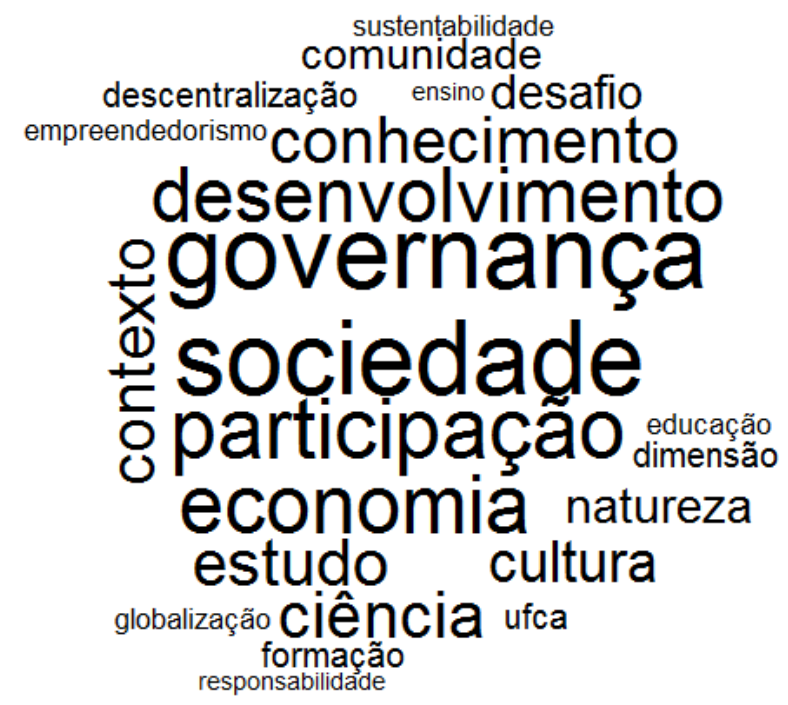

Fonte: Imagem elaborada pelos autores partir do soft Iramuteq.

Palavras como sociedade, governança, desenvolvimento, e economia se tornam termos primários, pois aparecem de forma expressiva, uma vez que as ementas fornecem uma frequência maior de ocorrências do uso desses termos no PPC, considerando as disciplinas obrigatórias e optativas do curso. As demais expressões se encontram associadas de forma subjacente aos termos primários e coaduna com a Política Nacional de Educação Ambiental instituída pela Lei n 9795/99, a qual dispõe:

\footnotetext{
Art. 10. A Educação Ambiental será desenvolvida como uma prática educativa integrada, contínua e permanente em todos os níveis e modalidades do ensino formal.

$\S 1^{\circ}$ A educação ambiental não deve ser implantada como disciplina específica no currículo de ensino.
}

Ou seja, o que é marcante em relação à educação ambiental é o seu caráter transversal e interdisciplinar, o que abre espaço para a possibilidade de que cada ementa de cada disciplina aborde a temática da maneira mais adequada à sua realidade. 
As diretrizes curriculares nacionais, publicadas em 2012, reafirmam essa relação da disciplina com foco no aspecto metodológico e dispõem que:

\footnotetext{
Art. 16. A inserção dos conhecimentos concernentes à Educação Ambiental nos currículos da Educação Básica e da Educação Superior pode ocorrer:

I - pela transversalidade, mediante temas relacionados com o meio ambiente e a sustentabilidade socioambiental;

II - como conteúdo dos componentes já constantes do currículo;

III - pela combinação de transversalidade e de tratamento nos componentes curriculares. Parágrafo único. Outras formas de inserção podem ser admitidas na organização curricular da Educação Superior e na Educação Profissional Técnica de Nível Médio, considerando a natureza dos cursos[...]
}

Desse modo, foi possível gerar através também do iramuteq, o gráfico de análise de similitude, que se trata de ligações entre as palavras previstas com corpus textual. Assim, se torna possível compreender mais sobre a forma de construção do texto e os temas presentes que sejam relevantes, tendo por base a ocorrência entre as diversas palavras, bem como as ligações semânticas estabelecidas nos documentos, aproximando o leitor da compreensão dos interesses que motivaram a criação deste curso, bem assim que devem impulsionar a gestão, os docentes e dos discentes em suas práticas.

Torna-se mais fácil, assim, a identificação da estrutura da base de dados, que neste caso é o corpus, diferenciando as partes que são mais comuns e as partes mais específicas.

Tal gráfico é produzido através da tabela de entrada, onde o pesquisador elenca os termos e expressões que sejam mais relevantes ao processo, assim, a matriz da similitude é calculada com o pressuposto dos scores dos termos escolhidos.

No caso visualiza-se que os termos escolhidos mais recorrentes são sociedade, desenvolvimento, natureza, cultura, desafio, sustentabilidade, e as demais, conforme se pode visualizar na imagem 2. Também, através desse gráfico é possível perceber que a citação do termo sociedade está fortemente ligada quando da citação do termo desenvolvimento, e em grau menor, quando da citação de natureza e ambiente.

Logo, verifica-se que sempre que era tratada da questão de sociedade, quase sempre se falava também de desenvolvimento, natureza e ambiente. Logo o discurso analisado, está ligado a esses conceitos, conforme se verifica na imagem abaixo. 
Imagem 2: Gráfico de análise de similitudes

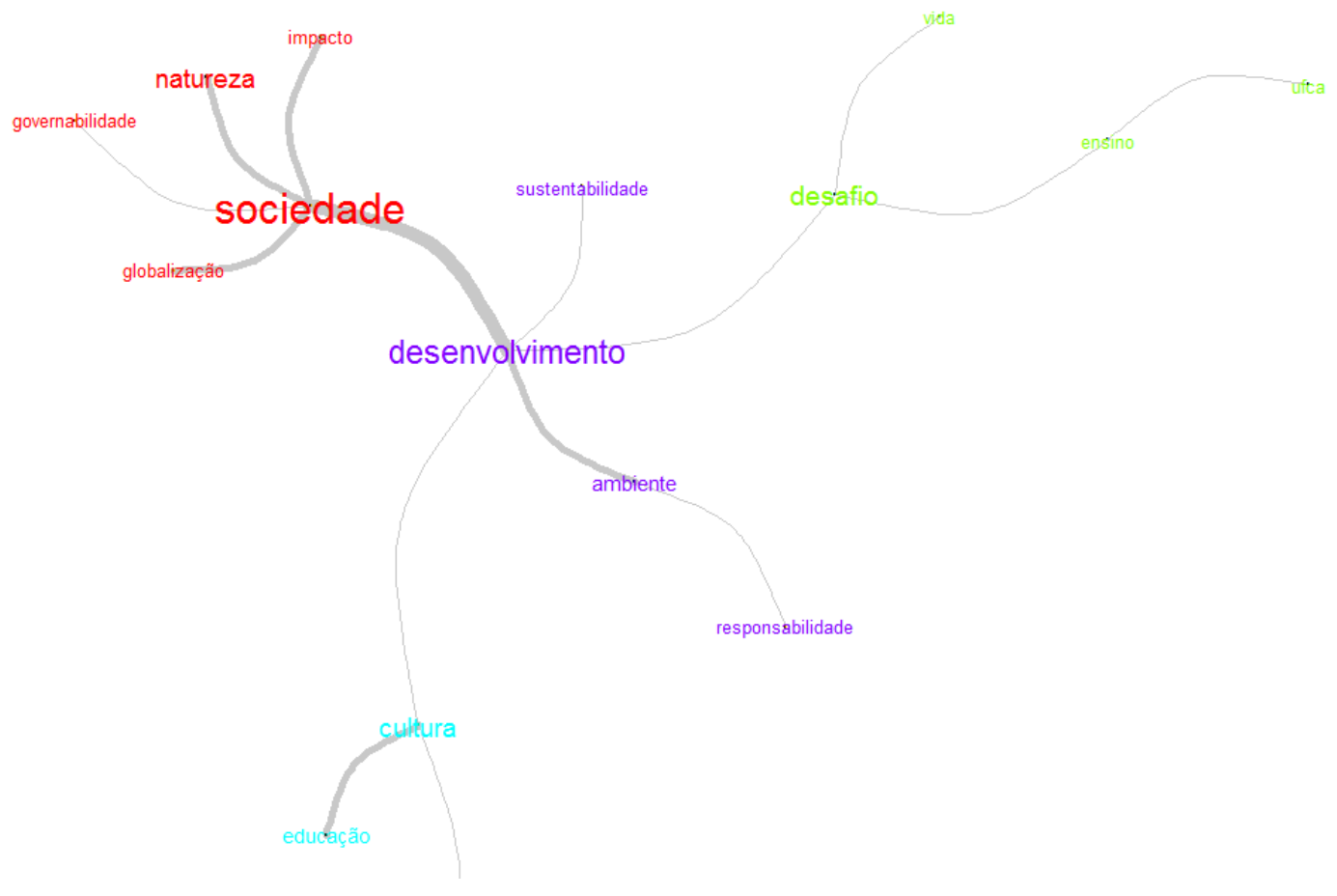

Fonte: Imagem elaborada pelo autor partir do soft Iramuteq.

O termo desenvolvimento aparece com destaque central do corpus submetido à modelagem por meio do Iramuteq. Vê-se que para a construção do PPC do curso de Administração Pública e Gestão Social da Universidade Federal do Cariri, tal evidencia revela-se significativa a medida que poderá direcionar os atores envolvidos na comunidade acadêmica em relação a construção de planos de aula, atividades, aulas de campo, avaliações, dentre outras.

\section{Considerações Finais}

A partir dessa breve análise da presença das dimensões da Sustentabilidade dentro do próprio PPC do curso em comento, evidencia-se a amplitude do discurso presente no referido documento, identificando desse modo, a perspectiva de desenvolvimento territorial de maneira harmônica dentro das propostas das unidades curriculares, sejam elas representadas 
por disciplinas obrigatórias e/ou optativas, nas bibliografias básicas ou complementares, refletindo o compromisso com o paradigma da Sustentabilidade para a Região Metropolitana do Cariri.

Entende-se então uma integração das dimensões da sustentabilidade à perspectiva de Desenvolvimento Regional Sustentável, ampliando assim o olhar e as possibilidades de abordagem e aplicação da Sustentabilidade com a visão individualizada, coletiva, comunitária, política e impreterivelmente ética.

Percebe-se ainda que no tocante à educação formal, entendida como aquela organizada conforme a Lei de Diretrizes e Bases da Educação, a qual vale-se da importância dada à educação ambiental, em especial pela Política Nacional de Educação Ambiental instituída pela Lei $n^{\circ}$ 9795/99, e pelo alinhamento dado através da Resolução $n^{\circ} 1$ de 2014 do CNE e em especial pela valorização do tema em relação ao PPC do Curso de Administração Pública e Gestão Social da UFCA, onde a Resolução CNE/CES 1/2014. Diário Oficial da União, Brasília, 13 de janeiro de 2014, demonstra uma valorização da temática, bem assim nos planos de ensino e no ementário das disciplinas.

Pensar sustentabilidade no contex to contemporâneo sob uma perspectiva sociopolítico, ambiental, econômica e humana nos convoca não somente à re(pensar) questões teóricas e metodológicas, mas também éticas e práticas para atuar na sociedade, com a sociedade e para a sociedade a curto, médio e logo prazo, nos colocando frente ao desafio de educarmos para a sustentabilidade. Os docentes e discentes do curso de Administração da UFCA têm a possibilidade de desenvolver uma relação pedagógica onde o foco volta-se para a formação de administradores públicos que bem saibam desenvolver a gestão social da coisa pública, com ética e probidade, imbuídos da compreensão de que estas são imprescindíveis à atuação de governos que possuam o desenvolvimento regional como norte para a implementação de suas políticas públicas de promoção do bem-estar social.

\section{Referências}

BADR, Eid et al. Educação Ambiental, conceitos, histórico, concepções e comentários à lei da Política Nacional de Educação Ambiental (Lei no 9.795/99): Programa de PósGraduação em Direito Ambiental da UEA: mestrado em Direito Ambiental / Org. Eid Badr. Vários autores - Manaus: Editora Valer, 2017.

581 Id on Line Rev. Mult. Psic. V.13, N. 46 p. 567-583, 2019 - ISSN 1981-1179 Edição eletrônica em http://idonline.emnuvens.com.br/id 
BENKO, George. Mundialização da Economia, Metropolização do Mundo. Revista do Departamento de Geografia, 15, 2002 45-54.

BOSSELMANN, K. The PrincipIe of Sustainability: Transforming Law and Governance. Ashgate Publishing Limited - 10 Klaus Bosselmann, 2008.

BRASIL. I Conferência Nacional de Desenvolvimento Regional. Documento de Referência, 2012.

BRASIL. Lei 9.795, de 27 de abril de 1999. Dispõe sobre a educação ambiental, institui a Política Nacional de Educação Ambiental e dá outras providências. Disponível em: < http:// www. planalto.gov.br/ccivil_03/leis/19795.htm >.

BRASIL, Ministério da Educação. Parâmetros Curriculares Nacionais: ciências naturais/Secretaria da Educação Fundamental. $2^{a}$ Ed, Rio de Janeiro: DP \& A, 2000.

BRASIL. Resolução CNE/CES n 9/2004. <http://portal.mec.gov.br/cne/arquivos /pdf/rces 09_04.pdf >.

BRASIL. Resolução CONSUNI/UFC n²8 2010.

<http://www.ufc.br/images/_files/a_universidade/consuni/resolucao_consuni_2010/resolucao 28_consuni_2010.pdf>.

BRASIL.ResoluçãoCNE/CESn'1/2014.<http://portal.mec.gov.br/index.php?option=com_do cman\&view=download $\&$ alias $=14957-$ rces001-14\&Itemid $=30192>$.

BRASIL. Ministério da Educação. Educação Ambiental: aprendizes de sustentabilidade. Cadernos SECAD 1. Brasília: MEC, 2007.

BRASIL, Ministério da Educação. Resolução CNE/CP no 2, de 15 de junho de 2012 Estabelece as Diretrizes Curriculares Nacionais para a Educação Ambiental. Disponível em < http://portal.mec.gov.br/index.php?option=com _docman\&view=download\&alias=10988-rcp002-12-pdf\&category_slug=maio-2012pdf\&Itemid=30192>.

BURSZTYN, M. (Org.). Ciência, ética e sustentabilidade: desafios ao novo século. São Paulo: Cortez; Brasília: UNESCO, 2001

GOERGEN, P. Pós-modernidade, ética e educação. 2.ed. Campinas: Autores Associados, 2005.

IRAMUTEQ. Interface do $\mathrm{R}$ para Análises Multidimensionais de Texto e Questionários. Software gratuito construído com software livre. Versão 0.7 alpha 2. Laboratório LERASS. 2014. Disponível em: <http://www.iramuteq.org/> .

582 Id on Line Rev. Mult. Psic. V.13, N. 46 p. 567-583, 2019 - ISSN 1981-1179 Edição eletrônica em http://idonline.emnuvens.com.br/id 
JARA, C. J; SOUTO, M.V. M, As Dimensões Intangíveis do Desenvolvimento Sustentável. Brasília: IICA, 2001.

LENA, L. Pobreza e Exclusão: traduções regionais de duas categorias da prática. Econômica: 4 (1): 25-59.

MARCOMIN, F. E; SILVA, A. D. V. Reflexões Acadêmicas: A sustentabilidade no ensino superior brasileiro: alguns elementos a partir da prática de educação ambiental na Universidade. CONTRAPONTOS - V. 9 nº 2 - pp. 104 - 117 - Itajaí, mai/ago 2009.

REIGOTA, M. O que é Educação Ambiental. Coleção Primeiros Passos. São Paulo: Brasiliense. 2001.

SEN, A. Desenvolvimento como liberdade. São Paulo, Companhia das Letras: 2000.

SACHS, I. Caminhos para o Desenvolvimento Sustentável. $3^{\text {a }}$ edição. Rio de Janeiro: Ed. Garamond, 2008.

SACHS, I. Desenvolvimento: includente, sustentável, sustentado. Rio de Janeiro:

Garamond, 2004.

SACHS, I. Estratégias de transição para o século XXI. In: BURSZTYN, M. Para Pensar o Desenvolvimento Sustentável. São Paulo: Brasiliense, 1993. p. 29-56.

SALVIATI, M. E. Manual do Aplicativo Iramuteq (versão 0.7 Alpha 2 e R Versão 3.2.3) compilação, organização e notas de 2017.

TAVARES, O. A. (Org). Projeto Político-Pedagógico do Curso de Bacharelado em Administração Pública e Gestão Social. Centro de Ciências Sociais Aplicadas - CCSA da Universidade Federal do Cariri (UFCA). Juazeiro do Norte: CCSA, 2016.

\section{Como citar este artigo (Formato ABNT):}

TEIXEIRA, Alcylanna Nunes; BRITO, Tamyris Madeira de; LOBO, Erich Costa Saraiva; QUEIROZ, Zuleide Fernandes de; FIRMINO, Paulo Renato Alves. Dimensões da Sustentabilidade no PPC do Curso de Bacharelado em Administração Pública e Gestão Social da Universidade Federal do Cariri (UFCA). Id on Line Rev.Mult. Psic., 2019, vol.13, n.46, p. 567-583. ISSN: 1981-1179.

Recebido: 04/07/2019;

Aceito: 09/07/2019. 